
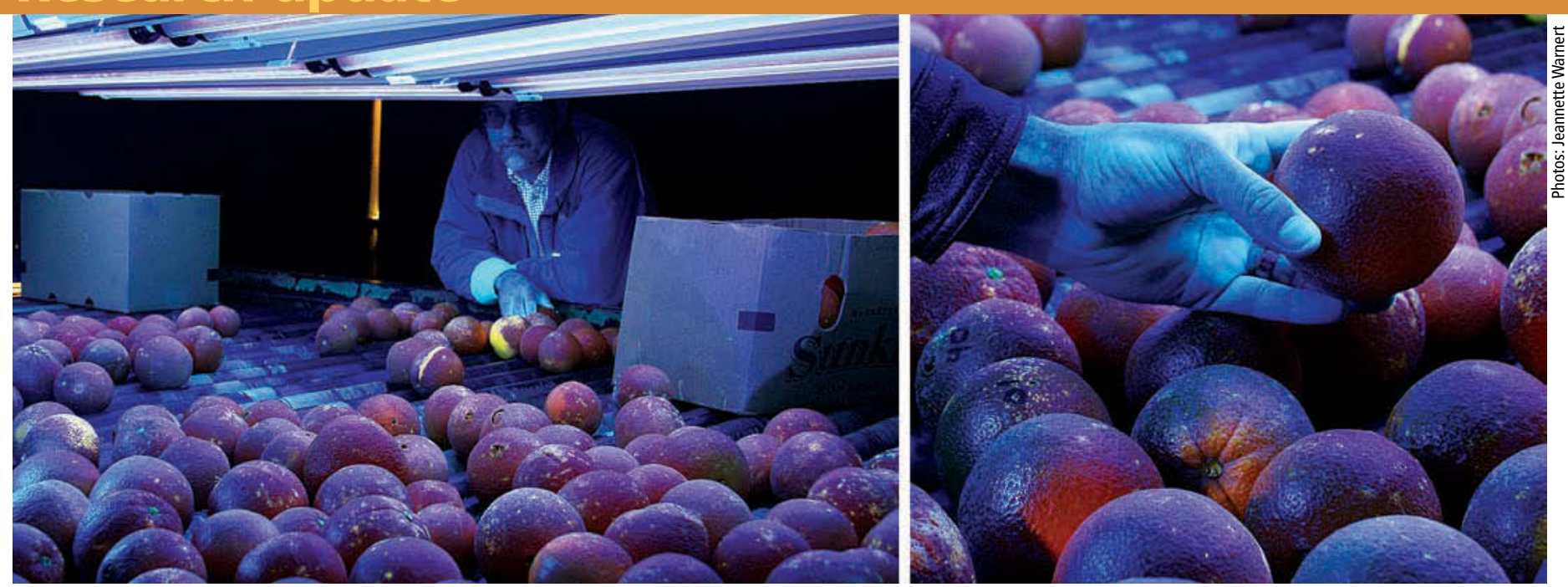

USDA plant physiologist David Obenland demonstrates the use of a blacklight to identify freeze-damaged oranges, which fluoresce with dots.

\title{
UV could cast new light on citrus damage
}

The toll of the January freeze on California agriculture is still being tallied by state officials, with the latest estimates hovering at $\$ 1.2$ billion and rising. But simple ultraviolet (UV) technology could make it possible for orange growers to estimate damage while fruit is still on the tree or in the packinghouse.

This year's freeze, which began in the wee hours of Jan. 12 and lasted anywhere from 5 to 15 days depending on the location, assaulted the state's agricultural crops with temperatures ranging from the teens to the high 20s.

A wide variety of California's fruit and vegetable crops were affected, including citrus, avocados, strawberries, artichokes, broccoli, celery, blueberries and cut flowers. Gov. Arnold Schwarzenegger has requested disaster relief for 24 of the state's 59 counties.

The biggest financial loss, about $\$ 700$ million, was shouldered by the state's citrus industry, followed by avocado growers with an estimated loss of $\$ 108$ million.

"Our most recent estimate is a $27 \%$ loss for avocadoes," says Tom Bellamore, senior vice president of the California Avocado Commission. "The hardest hit areas were San Luis Obispo, the San Joaquin Valley, Fillmore and the Ojai area of Ventura County."

Citrus farmers expect damage when temperatures drop below $28^{\circ} \mathrm{F}$ for more than 5 or 6 hours, so the extended period of cold nights hit especially hard.

Farmers made efforts to save their crops by blowing warmer air through 30 -foot wind machines and irrigating trees, but in most cases fruit still sustained some damage.
Ted A. Batkin, president of the Citrus Research Board, estimated losses of about $45 \%$ for freshmarket citrus products and 35\% overall, which accounts for juice recovery. Citrus growers began harvesting the navel orange crop in late October, more than 2 months before the freeze set in, so about $30 \%$ of the crop had already been harvested. That left about $70 \%$ still on the trees during the cold snap. "It looks like we are recovering 30\% to $40 \%$ of what was left on the trees," Batkin says.

\section{New technology to estimate damage}

Loss estimates for the 2007 freeze are still somewhat fluid because it is difficult for citrus growers to determine exactly how much freeze damage fruit has incurred.

Currently, the industry needs to cut open fruit to see if it has been damaged. But this approach is far from foolproof, says Mary Lu Arpaia, UC Cooperative Extension subtropical horticulture specialist and member of the UC Riverside botany and plant sciences department. "Fruit-cutting is a laborious process," Arpaia explains. For several weeks after a freeze, fruit are evaluated using the "segment cut," in which the middle third of the fruit is opened up to examine the segment walls.

But that may be changing.

One upside of the freeze is that the scientists have been able to go out into orange groves to test a new method that utilizes ultraviolet (UV) light to assess freeze damage while fruit is still on the trees, without cutting the fruit.

Funded by the Citrus Research Board and headed by Jim Thompson, UC Cooperative Extension agricultural engineering specialist at 
A new ANR Communication Services book, Home Orchard: Growing Your Own Deciduous Fruit and Nut Trees, was developed for backyard orchardists, rare fruit growers and small-scale growers; go to http:// anrcatalog.ucdavis.edu for more information.

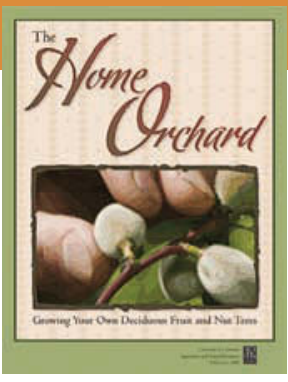

UC Davis, a group of UC and U.S. Department of Agriculture (USDA) scientists appear to have identified a nondestructive method.

Researchers in the lab of USDA plant physiologist David Obenland and USDA plant pathologist Dennis Margosan noticed that the outside peel of freeze-damaged oranges fluoresces with yellow pinpoint dots when put under UV fluorescent light (UVA at 365 nanometers wavelength). "Freezing causes tiny amounts of orange oil to become visible on the rind's surface," Thompson says. "The specks of oil glow like stars on a moonless night when exposed to blacklight."

The group started testing the method last spring in the lab with artificially frozen fruit, but with this year's freeze they had an opportunity to test it with a simple UV flashlight in orange groves at night and in blacklight rooms inside packinghouses. Already they've found differences between the lab and the field.

"The fluorescence was not as dramatic as when you put fruit in the freezers," says Arpaia, who joined the team for the validation phase of the research. "We have had to recalibrate." They are also investigating how long fluorescence lasts on the fruit.

In addition, the team is doing preliminary testing to see if different kinds of navel oranges fluoresce differently. The material that fluoresces in some citrus fruit is called "tangeritin," which is found in the peel of oranges, grapefruit and some mandarins; it is not found in lemons and therefore, they do not fluoresce. Likewise, the method does not appear to work in other, noncitrus crops.

The researchers also tested another potential method of evaluating frost damage in oranges using a Breathalyzer, a tool more commonly used by law enforcement to identify drunk drivers. Frostdamaged oranges emit ethanol, so researchers placed samples of damaged fruit into closed plastic bags for 20 to 30 minutes, then used a Breathalyzer fitted with a hypodermic needle (instead of a mouthpiece) to measure the amount of ethanol produced. The initial field tests showed the technique was not as reliable as UV light.

"We're hoping we have some of these variables worked out," Arpaia says. "We have more work to do before the next freeze."

\section{- Celeste Durant and Editors}

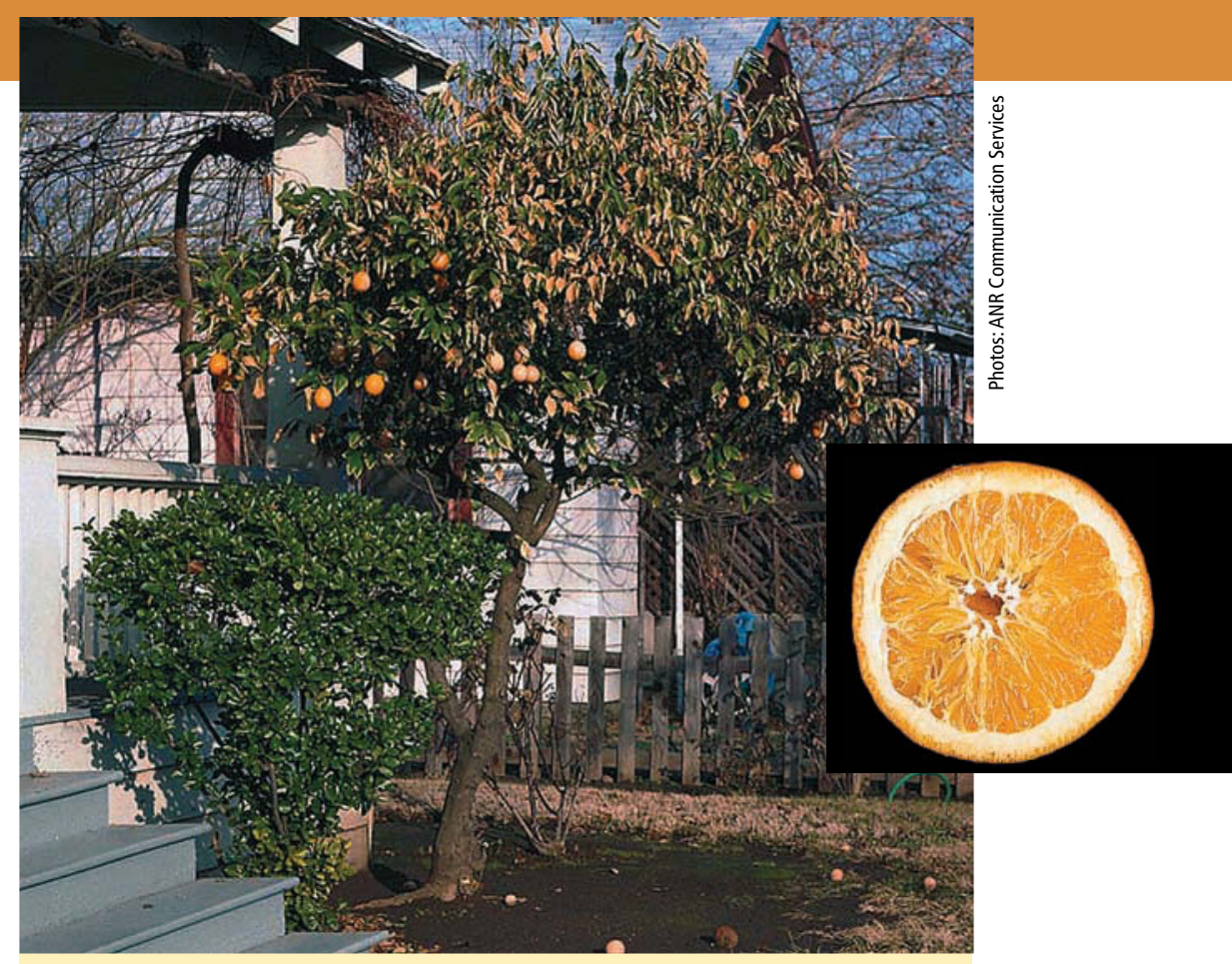

Freeze-damaged tree and fruit.

\section{Frost-damaged plants may need pruning, but wait until spring}

Freezing temperatures in many parts of California injured some citrus trees and other frost-sensitive subtropical plants in January, but since the full extent of injury can not be known for several months, UC Cooperative Extension (UCCE) horticulture advisor Ed Perry recommends that gardeners wait until spring before pruning and removing damaged trees and plants.

"While you may be tempted to prune out damaged branches right away, it's best to wait until spring when new growth will show you the extent of the injury," says Perry of Stanislaus County. "Earlier pruning often results in leaving some limbs which might continue to die back, and the removal of limbs which might recover."

Frost injury to plants depends upon a number of factors, including species, age, health, soil moisture and location. Frost injures plants by causing ice crystals to form in plant cells, making water unavailable to plant tissues and disrupting the movement of fluids. Frost-damaged leaves appear water-soaked, wither, and turn dark brown or black. Unprotected, sensitive young trees may be killed, but frost rarely kills mature trees in California.

The only treatments that should be applied rapidly after a freeze are whitewashing to prevent "sunburn" and picking frost-damaged fruit to remove stress from the tree, says UCCE citrus farm advisor Ben Faber of Ventura County.

The UC advisors also recommend withholding nitrogen fertilizer applications to severely damaged citrus trees and irrigating carefully. Over-irrigation may induce root damage and encourage the growth of root-rotting organisms. Irrigation should be less frequent and in smaller amounts until trees have regained their normal foliage. - Jeannette Warnert 